\title{
ESTERIFICAÇÃO E TRANSESTERIFICAÇÃO SIMULTÂNEAS DO ÓLEO DE ANDIROBA UTILIZANDO ÓXIDO DE NIÓBIO-SULFATO COMO CATALISADOR
}

\author{
M. D. POLICANO ${ }^{1}$, J. D. RIVALDI ${ }^{1}$; L. M. CARNEIRO ${ }^{1}$, H.F. DE CASTRO ${ }^{1}$ \\ ${ }^{1}$ Universidade de São Paulo, Escola de Engenharia de Lorena \\ E-mail para contato: martim@alunos.eel.usp.br
}

\begin{abstract}
RESUMO - A crescente procura pela sustentabilidade econômica da produção de biodiesel estimula pesquisas para a diversificação da matéria-prima e aumento dos rendimentos mediante desenvolvimento de novos catalisadores. Neste sentido, a catálise ácida heterogênea possibilita a utilização de óleos com alto conteúdo de ácidos graxos livres, normalmente descartados para processos de conversão alcalina devido à saponificação e dificuldade de purificação do produto final. Neste trabalho, foi desenvolvido o catalisador óxido de nióbio $/ \mathrm{H}_{2} \mathrm{SO}_{4}$ obtido por impregnação de $\mathrm{Nb}_{2} \mathrm{O}_{5}$ com $\mathrm{H}_{2} \mathrm{SO}_{4}(0,5 \mathrm{~mol} / \mathrm{L})$ a $100{ }^{\circ} \mathrm{C}$ sob refluxo e agitação constante. $\mathrm{O}$ catalisador foi submetido a tratamento térmico a $500^{\circ} \mathrm{C}$ por $5 \mathrm{~h} \mathrm{e}$ caracterizado quanto ao volume de poros (wet point), umidade e acidez titulável $(\mathrm{mmol} \mathrm{H}+/ \mathrm{g})$. A reação simultânea de esterificação e de transesterificação foi conduzida em reator de aço tipo ampola e reator pressurizado, com óleo de andiroba (índice de acidez: $33,1 \mathrm{mg} \mathrm{KOH} / \mathrm{g}$ ) e etanol anidro a $250^{\circ} \mathrm{C}$, relação molar óleo:etanol 1:120 e concentração de catalisador óxido de nióbio/ $\mathrm{H}_{2} \mathrm{SO}_{4}$ de $20 \%(\mathrm{~m} / \mathrm{m}$ em relação a massa de óleo). Conversões mais elevadas foram obtidas em reator pressurizado, concentrações de ésteres da ordem 90,9\% em 3 horas de reação.
\end{abstract}

\section{INTRODUÇÃO}

A busca da diversificação da matriz energética nacional vem estimulando o surgimento de novas estratégias para aprimorar a produção e redução de custos dos biocombustíveis, incluindo o biodiesel. O biodiesel é produzido pela transesterificação de óleo vegetal e álcool (metanol ou etanol) na presença de catalisador químico homogêneo ou heterogêneo. O metanol é um álcool de baixo custo utilizado preferencialmente em países produtores de petróleo e que apresenta maior reatividade que álcoois de cadeia carbônica maior (Brandão et al., 2010).

Devido à abundância de etanol no mercado nacional, o biodiesel brasileiro é produzido principalmente por etanólise de óleo vegetal, incluindo óleo de soja, algodão e palma (Rocha et al., 2010). Entretanto, existe a necessidade da busca de fontes alternativas de lipídeos para a 
redução de custos de produção de biodiesel, e ao mesmo tempo, reduzir a competição com a produção alimentar.

Óleos vegetais considerados não comestíveis, como andiroba, macaúba e pinhão manso, são matérias-primas alternativas para a produção de biodiesel. $\mathrm{O}$ alto valor de acidez destes óleos constitui um inconveniente para a catálise básica tradicional, uma vez que os ácidos graxos livres do óleo reagem com o catalisador originando ésteres de sódio ou potássio (sabão). Esta reação secundária dificulta o processo de separação do glicerol e ésteres no processo de purificação do produto final, diminuindo o rendimento e aumentado as etapas de purificação. Neste sentido, os catalisadores heterogêneos ácidos constituem uma alternativa para contornar os problemas de saponificação derivados do uso de catalisadores alcalinos, facilitando ao mesmo tempo a recuperação de produto e do próprio catalisador em menor número de etapas (Kiss et al., 2006).

O grande investimento no setor de produção de biodiesel e a necessidade da busca de novas matérias-primas e insumos para a indústria de biodiesel estimula a síntese de novos catalisadores, capazes de promover a conversão de matéria-prima de elevada acidez. Neste sentido, o presente trabalho teve como objetivo o desenvolvimento de catalisador heterogêneo ácido a base de óxido de nióbio/ $\mathrm{H}_{2} \mathrm{SO}_{4}$ para sua utilização em reações simultâneas de esterificação e transesterificação para produção de ésteres etílicos a partir de óleo vegetal de elevada acidez.

\section{MATERIAL E MÉTODOS}

\subsection{Materiais}

Ácido nióbico (óxido de nióbio hidratado) amorfo com teor da ordem de $80 \%$ em $\mathrm{Nb}_{2} \mathrm{O}_{5}$ foi gentilmente cedido pela Companhia Brasileira de Metalurgia e Mineração (Minas Gerais) e utilizado como base para a preparação do catalisador. Óleo de andiroba foi gentilmente doado pela Pulcra (Jacareí - SP), apresentando a seguinte composição em ácidos graxos (g/g): 0,1\% Láurico; 0,1 \% Mirístico; 29,0\% Palmítico; 10,0\% Esteárico; 47\% Oleico e 10,7\% Linoleico (Carvalho et al., 2015). Etanol anidro (98\%, Vetec) foi utilizado como agente acilante.

\subsection{Preparação do catalisador óxido de nióbio sulfatado}

$\mathrm{O}$ óxido de nióbio sulfatado $\left(\mathrm{Nb}_{2} \mathrm{O}_{5} / \mathrm{H}_{2} \mathrm{SO}_{4}\right)$ foi preparado a partir de uma mistura de 5 $\mathrm{g}$ de óxido de nióbio, $5 \mathrm{~mL}$ de $\mathrm{H}_{2} \mathrm{SO}_{4}(0,5 \mathrm{M})$ e $15 \mathrm{~mL}$ de água deionizada em reator de vidro a $90^{\circ} \mathrm{C}$ sob refluxo e agitação constante $(500 \mathrm{rpm})$ por $3 \mathrm{~h}$. O material filtrado foi seco a $100^{\circ} \mathrm{C}$ por $12 \mathrm{~h}$. Em seguida, a amostra foi submetida a tratamento térmico a $500^{\circ} \mathrm{C}$ por $5 \mathrm{~h}$.

\subsection{Catálise heterogênea ácida}

O catalisador sintetizado foi avaliado quanto ao poder catalítico em reações simultâneas de esterificação e de transesterificação. $\mathrm{O}$ catalisador foi seco a $120^{\circ} \mathrm{C}$ por $2 \mathrm{~h}$ antes de sua utilização. As reações foram conduzidas em reator (tipo ampola) de aço inoxidável com 
volume útil de $85 \mathrm{~mL}$ e reator pressurizado ALPHATEC de $250 \mathrm{~mL}$ de volume útil. As reações foram conduzidas a $250{ }^{\circ} \mathrm{C}$, razão molar de etanol para óleo de 120 e concentração de catalisador $(20 \% \mathrm{~m} / \mathrm{m}$ em relação à massa de óleo). A pressão interna do reator correspondeu à pressão de vapor do componente mais volátil da mistura reacional. O sistema reacional foi mantido sobre aquecimento e agitação magnética constante por um período máximo de $8 \mathrm{~h}$.

\subsection{Purificação de ésteres etílicos}

Ao término de cada reação, o meio reacional foi resfriado e centrifugado a $1570 \times \mathrm{g}$ por 15 minutos para sedimentação do catalisador. O sobrenadante foi purificado conforme metodologia descrita por Carvalho et al., (2015).

\subsection{Metodologia analítica}

Os valores de índice de acidez, umidade, densidade e viscosidade absoluta do óleo e ésteres produzidos foram determinados, conforme metodologia descrita por Carvalho et al. (2015).

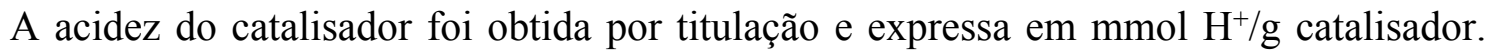
Para tanto, $100 \mathrm{mg}$ de catalisador foram deixados em contato com $20 \mathrm{~mL}$ de $\mathrm{NaOH} 0,1 \mathrm{M}$ por $3 \mathrm{~h}$ sob agitação suave. Em seguida, foram obtidas alíquotas da solução básica e titulada com $\mathrm{HCl} \mathrm{0,1} \mathrm{M} \mathrm{para} \mathrm{determinação} \mathrm{da} \mathrm{quantidade} \mathrm{de} \mathrm{NaOH}$ que reagiu com o material.

O catalisador, previamente seco a $100{ }^{\circ} \mathrm{C}$, foi analisado quanto ao volume de poros mediante a técnica de wet point ou ponto úmido. Utilizando-se uma micropipeta foi adicionada água ultra-pura no catalisador sob agitação constante até observação da formação de aglomerados de sólidos. Os resultados foram expressos em volume de água necessários por grama de catalisador $(\mathrm{mL} / \mathrm{g})$.

O rendimento de conversão do óleo de andiroba em ésteres etílicos foi determinado por Ressonância Magnética Nuclear $\left(\mathrm{RMN}^{1} \mathrm{H}\right)$ em espectrômetro Varian Mercury $300 \mathrm{MHz}$, utilizando clorofórmio deuterado $\left(\mathrm{CDCl}_{3}\right)$ como solvente e $0,3 \%$ de tetrametilsilano (TMS) como padrão interno (Carvalho et al., 2015). A determinação das concentrações de monoacilgliceróis, diacilgliceróis e triacilgliceróis foi realizada por Cromatografia Líquida de Alta Eficiência (CLAE), de acordo com metodologia descrita por Carvalho et al., (2015).

\section{RESULTADOS E DISCUSSÃO}

Na Tabela 1 são apresentados os valores de acidez titutável e volume de poros do catalisador e suporte. $\mathrm{O}$ valor de acidez de $2,764 \mathrm{mmol} \mathrm{H}^{+} / \mathrm{g}$ indica a impregnação efetiva de grupos sulfato na estrutura cristalina do óxido de nióbio, valor 67 vezes superior ao da acidez

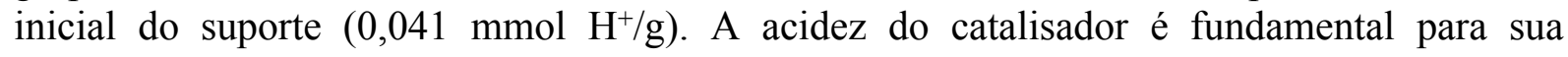
utilização em processos de conversão de óleos ácidos em ésteres etílicos. 
Verifica-se ainda na Tabela 1 a redução de 40\% no volume de poros do óxido de nióbio sulfatado em relação ao óxido de nióbio, confirmando a impregnação do ácido sulfúrico no suporte.

Tabela 1 - Acidez titulável e volume de poros dos catalisadores.

\begin{tabular}{lcc}
\hline Catalisador & $\begin{array}{c}\text { Acidez titulável } \\
(\mathbf{m m o l ~ H} / \mathbf{g})\end{array}$ & $\begin{array}{c}\text { Volume de poros* } \\
(\mathbf{m L} / \mathbf{g})\end{array}$ \\
\hline $\mathrm{Nb}_{2} \mathrm{O}_{5}$ (suporte) & 0,041 & 0,207 \\
$\mathrm{Nb}_{2} \mathrm{O}_{5} / \mathrm{H}_{2} \mathrm{SO}_{4}$ & 2,764 & 0,124 \\
\hline * wet point & &
\end{tabular}

As propriedades físico-químicas do óleo utilizado no presente trabalho são apresentadas na Tabela 2. O valor de acidez do óleo de andiroba foi $31,11 \mathrm{mg} \mathrm{KOH} / \mathrm{g}$, superando 6,6 vezes o limite superior dos óleos vegetais considerados não ácidos. $O$ índice de acidez está relacionado diretamente com a concentração de ácidos graxos livres e denota o grau de degradação parcial dos triglicerídeos presentes no óleo vegetal. Óleos com valores de acidez superiores a 5,0 $\mathrm{mg} \mathrm{KOH} / \mathrm{g}$, quando transesterificados na presença de catalisadores homogêneos básicos, promovem a saponificação, desativação do catalisador e formação de água (Knothe et al., 2006).

Tabela 2- Propriedades físico-químicas do óleo de andiroba (Carapa guianensis)

\begin{tabular}{lc}
\hline \multicolumn{1}{c}{ Propriedade } & Valor \\
\hline Massa molar $(\mathrm{g} / \mathrm{mol})$ & 830 \\
Viscosidade $\left(\mathrm{mm}^{2} / \mathrm{s}\right)$ & 35,7 \\
Densidade $\left(\mathrm{kg} / \mathrm{m}^{3}\right)$ & 931 \\
Umidade $(\%)$ & $<1$ \\
Acidez $(\mathrm{mg} \mathrm{KOH} / \mathrm{g})$ & 33,11 \\
\hline
\end{tabular}

$\mathrm{O}$ desempenho catalítico do óxido de nióbio $/ \mathrm{H}_{2} \mathrm{SO}_{4}$ foi avaliado na síntese de ésteres etílicos a partir do óleo de andiroba em reator de ampola e reator pressurizado.

Os valores de conversão do óleo de andiroba em ésteres etílicos e viscosidade ao longo do tempo de reação, realizada em reator ampola, são apresentados na Figura 1. O rendimento de ésteres etílicos foi calculado a partir dos espectros de $\mathrm{H}^{1}$-NMRN. Observa-se que o perfil de rendimento em ésteres etílicos aumentou gradativamente com o tempo até alcançar o valor máximo de $67 \%$ em $7 \mathrm{~h}$ de reação. Em relação ao perfil de viscosidade, constata-se uma redução de $74 \%\left(8,2 \mathrm{~mm}^{2} / \mathrm{s}\right)$ em relação ao valor inicial do óleo de andiroba $\left(35,7 \mathrm{~mm}^{2} / \mathrm{s}\right)$, conforme esperado a viscosidade do produto decresceu com o aumento da conversão do óleo em ésteres etílicos. 

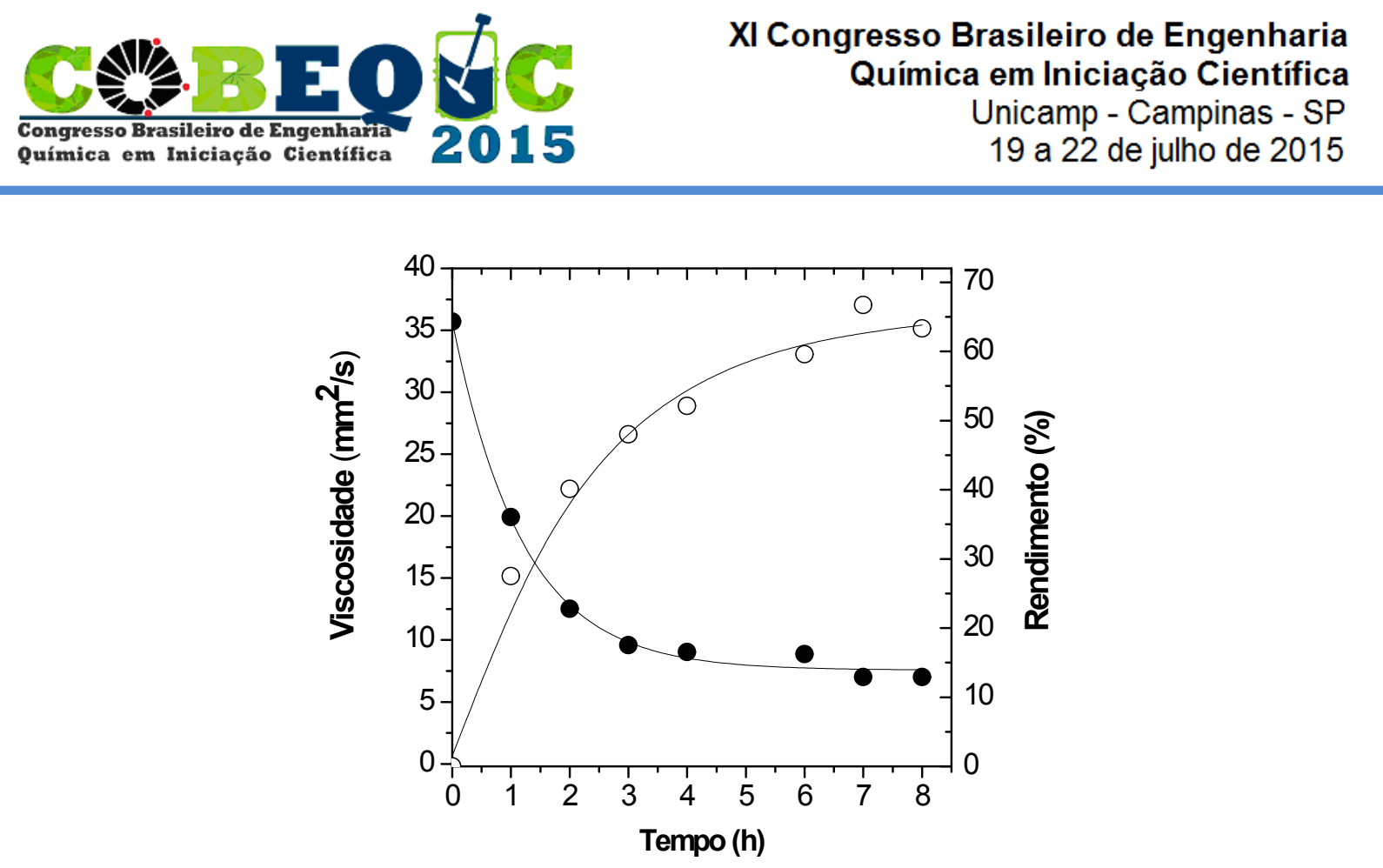

Figura 1 - Perfil de rendimento de reação $(\mathrm{O})$ e viscosidade cinemática dos ésteres etílicos $(\bullet)$ em função do tempo reacional

Os valores médios da reação do óleo de andiroba em ésteres etílicos em reator pressurizado são apresentados na Tabela 3. Em 3 horas de reação a conversão alcançada foi de $90,9 \%$. Este valor é superior ao observado no reator tipo ampola, provavelmente em função do controle mais efetivo das condições operacionais (temperatura, pressão e agitação). Os teores de monoacilgliceróis e diacilgliceróis encontrados foram 8,1 e 1,0\%, respectivamente.

Tabela 3 - Características dos ésteres etílicos produzidos por esterificação e transesterificação simultãnea do óleo de andiroba em reator pressurizado

\begin{tabular}{lc}
\hline Parâmetro & Valor \\
\hline Rendimento (\%) & 90,9 \\
Viscosidade cinemática $\left(\mathrm{mm}^{2} / \mathrm{s}\right)$ & 5,9 \\
Densidade $\left(\mathrm{kg} / \mathrm{m}^{3}\right)$ & 879 \\
Monoacilgliceróis (\%) & 8,10 \\
Diacilgliceróis (\%) & 1,0 \\
Triacilgliceróis $(\%)$ & 0 \\
Acidez $(\mathrm{mg} \mathrm{KOH} / \mathrm{g})$ & 6,5 \\
\hline
\end{tabular}

Na metanólise do óleo de soja utilizando óxido de nióbio-sulfato como catalisador, Pietre et al., (2010) reportaram rendimentos de 40\% em ésteres metílicos em reações conduzidas a $70^{\circ} \mathrm{C}$ por $5 \mathrm{~h}$. Em outro trabalho, Rocha et al., (2010) relataram a utilização de óxido de nióbio na hidroesterificação do óleo de soja, obtendo rendimentos de $87 \%$. 
Geralmente, a atividade catalítica diminui com o comprimento de cadeia alquílica do álcool devido ao efeito estérico, assim, o etanol apresenta menor reatividade que o metanol em reações de transesterificação. Este efeito observado em catálise tanto em condições alcalinas como ácidas pode ser reduzido por meio do aumento da razão molar do álcool para óleo. Brandão et al., (2009) relataram a conversão de ácidos graxos livres, derivados da hidrólise do óleo de soja, em éster por metanólise alcançando rendimento de $57 \%$ após $2 \mathrm{~h}$ de reação a $160^{\circ} \mathrm{C}$.

\section{CONCLUSÃO}

A conversão de óleo de andiroba mediante o catalisador óxido de nióbio $/ \mathrm{H}_{2} \mathrm{SO}_{4}$ apresentou rendimento máximo de $90,9 \%$ em ésteres etílicos. Este resultado demonstra a efetividade do catalisador heterogêneo desenvolvido para a esterificação e transesterificação simultânea de óleo com alto conteúdo em ácidos graxos livres. Estudos visando reduzir os teores residuais de mono e diacilgliceróis estão em fase de desenvolvimento.

\section{REFERÊNCIAS}

CARVALHO, A. K. F.; FARIA, E. L. P.; RIVALDI, J.D.; ANDRADE, G.S.S.; OLIVEIRA, P.C.; DE CASTRO, H. F. Performance of whole-cells lipase derived from Mucor circinelloides as a catalyst in the ethanolysis of non-edible vegetable oils under batch and continuous run conditions. Ind. Crop Prod., v. 60, p. 287-294, 2015.

BRANDÃO, R.F.; QUIRINO, R.L.; MELLO, V.M.; TAVARES, A.P.; PERS, A.C.; GUINHOS, F.; RUBIM, J.C.; SUAREZ, P.A. Synthesis, characterization and use of $\mathrm{Nb}_{2} \mathrm{O}_{5}$ based catalysts in producing biodiesel by transesterification, esterification and pyrolysis. J. Braz. Chem. Society, v.20, p.954-966, 2009.

KISS, A.A.; DIMIAN, A.C.; ROTHENBERG, G. Solid acids catalysts for biodiesel production-towards sustainable energy. Adv. Synth. Catal., v. 348, p. 75- 81, 2006 a.

KNOTHE, G.; GERPEN, J. V.; KRAHL, J.; RAMOS, L. P. Manual do Biodiesel, $1^{\text {a }}$ ed. São Paulo: Edgard Blucher, 2006.

PIETRE, M.K.; ALMEIDA, L.C.P.; LANDERS, R.; VINHAS, R.C.G.; LUNA, F.J. $\mathrm{H}_{3} \mathrm{PO}_{4}{ }^{-}$ and $\mathrm{H}_{2} \mathrm{SO}_{4}$-treated niobic acid as heterogeneous catalyst for methyl ester production. Reac. Kinet. Mech. Cat., v. 99, p. 269-280, 2010.

ROCHA, L. L.; RAMOS, A. L.; ANTONIOSI FILHO, N. R.; FURTADO, N. C.; TAFT, C. A.; ARANDA, D. A. G. Production of biodiesel by a two-step niobium oxide catalyzed hydrolysis and esterificatioin. Lett. Org. Chem., v.7, p. 571-578, 2010. 